This is an author produced version of a paper published in Journal of

Chemical Ecology. This paper has been peer-reviewed and is proofcorrected, but does not include the journal pagination

Citation for the published paper:

Jonas M. Bengtsson, Satya Prabhakar Chinta, Yitbarek Wolde-Hawariat, Merid Negash, Emiru Seyoum, Bill S. Hansson, Fredrik Schlyter, Stefan

Schulz and Ylva Hillbur. (2010) Pheromone-based Mating and Aggregation in the Sorghum Chafer, Pachnoda interrupta. Journal of Chemical Ecology. Volume: 36 Number: 7, pp 768-777. http://dx.doi.org/10.1007/s10886-010-9814-2

Access to the published version may require journal subscription.

Published with permission from: Springer Netherlands

The original publication is available at www.springerlink.com

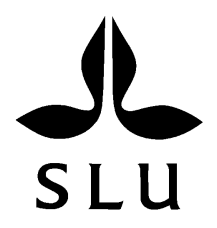

Epsilon Open Archive http://epsilon.slu.se 


\title{
Pheromone-based Mating and Aggregation in the Sorghum Chafer, Pachnoda interrupta
}

\author{
Jonas M. Bengtsson*1,2 ${ }^{1,}$ Satya Prabhakar Chinta ${ }^{3}$ - Yitbarek Wolde-Hawariat ${ }^{1,4,5} \bullet$ \\ Merid Negash $^{4,6} \bullet$ Emiru Seyoum $^{4} \bullet$ Bill S. Hansson ${ }^{1,6} \bullet$ Fredrik Schlyter $^{1} \bullet$ Stefan \\ Schulz $^{3} \bullet$ Ylva Hillbur $^{1}$ \\ ${ }^{1}$ Department of Plant Protection Biology, Swedish University of Agricultural Sciences, \\ PO Box 102, 23053 Alnarp, Sweden \\ ${ }^{2}$ IASMA Research and Innovation Center, Fondazione E. Mach, Via E. Mach 1, 38010, \\ San Michele all'Adige, Italy (current address) \\ ${ }^{3}$ Institute of Organic Chemistry, Technische Universität Braunschweig, Hagenring 30, \\ Braunschweig, Germany \\ ${ }^{4}$ Department of Biology, Addis Ababa University, PO Box 1176, Addis Ababa, Ethiopia \\ ${ }^{5}$ Department of Plant Sciences, Wollo University, PO Box 1145, Dessie, Ethiopia \\ ${ }^{6}$ Department of Evolutionary Neuroethology, Max Planck Institute for Chemical Ecology, \\ Hans-Knoell-Strasse 8, Jena, Germany
}

*To whom correspondence should be addressed. E-mail: Jonas.Bengtsson@iasma.it

\begin{abstract}
Adults of the sorghum chafer, Pachnoda interrupta Olivier (Coleoptera: Scarabaeidae: Cetoniinae), form aggregations during the mating period in July, but also in October. The beetles aggregate on food sources, e.g., Acacia spp. trees or sorghum with ripe seeds, to feed and mate. During the mating season, field trapping experiments with live beetles as bait demonstrated attraction of males to unmated females, but not to mated females or males, indicating the presence of a female-emitted sex pheromone. Unmated females combined with banana (food source) attracted significantly more males and females than did unmated females alone. Other combinations of beetles with banana were not more attractive than banana alone. Thus, aggregation behavior appears to be guided by a combination of pheromone and host volatiles. Females and males were extracted with hexane during the mating period, and the extracts were compared by using GC-MS. In a field trapping experiment, 19 compounds found only in females were tested, both singly and in a mixture. Traps baited with one of the female-associated compounds, phenylacetaldehyde, caught significantly more beetles than any other treatment. However, the sex ratio of beetles caught in these traps did not differ from that of control traps and it is possible that other components may be involved in the sex pheromone signal. Furthermore, traps baited with a mixture of all 19 compounds attracted significantly fewer beetles than did phenylacetaldehyde alone.
\end{abstract}

Keywords Aggregation pheromone $\bullet$ Coleoptera $\bullet$ Field trapping $\bullet$ Gas chromatographyMass spectrometry (GC-MS) • Olfaction • Pachnoda interrupta $\bullet$ Phenylacetaldehyde $\bullet$ Scarabaeidae $\bullet$ Semiochemicals $\bullet$ Sex pheromone $\bullet$ Sorghum $\bullet$ Sorghum bicolor 


\section{Introduction}

The sorghum chafer, Pachnoda interrupta Olivier (Coleoptera: Scarabaeidae: Cetoniinae), is present in semi-arid parts of Africa subject to strong seasonal variation in rainfall and temperature, mainly in the Sahel and Sudan ecoregions (Schmutterer 1969; Grunshaw 1992; Jago 1995; Sastawa and Lale 2000), but also parts of Ethiopia (Hiwot 2000). As a reflection of the climatic conditions, the growth and abundance of plants is highly seasonal in these regions (White 1983), especially with regard to fruits and flowers, on which the polyphagous adults of P. interrupta feed (Clark and Crowe 1978; Grunshaw 1992; Hiwot 2000). During the dry period, which lasts approximately from November to May, adult P. interrupta estivate in the soil under trees and bushes (WoldeHawariat et al. 2007). After the short rains in June, adult beetles emerge to feed and mate, often forming dense aggregations on food sources, e.g., flowering Acacia spp. The mating season ends with the onset of the rainy season, when the females oviposit in the topsoil. The larvae develop in the soil, feeding on plant litter, and pupate towards the end of the rains, in August (Seneshaw and Mulugeta 2002). New adults emerge in September-October and feed intensively before going into estivation.

During the September-October feeding period, the sorghum chafer can be a devastating pest on sorghum, Sorghum bicolor (L.) Moench (Poaceae), causing mean yield loss of up to $70 \%$ in severely affected areas of Ethiopia (Yitbarek and Hiwot 2000). Efficient control methods are not available, but farmers trap adults with simple containers baited with fruit (Ministry of Agriculture and Ethiopian Agricultural Research Organization 1999). Traps baited with a combination of food (e.g., fruit) and pheromones have proved to be efficient for control of several beetle species that are pests on commercial crops (Alpizar et al. 2002; Oehlschlager et al. 2002). Field observations of mating and aggregation in adult $P$. interrupta led us to suspect that a pheromone could be involved in these behaviors. We performed field experiments and chemical analyses to investigate whether this was the case. The identification of pheromone compound(s) used in mating or aggregation could enable the development of highly attractive lures that could be employed in mass trapping of this pest.

\section{Methods and Materials}

General Methods in Field Experiments In all field experiments, Japanese beetle traps (Trécé, Palo Alto, CA, USA) were suspended from wooden poles ca. $3 \mathrm{~m}$ above ground. Except where otherwise noted, a complete randomized block design $(N=10)$ was used, with $10 \mathrm{~m}$ between traps and at least $50 \mathrm{~m}$ between blocks. Traps were emptied and lures replaced each morning.

Field Activity Patterns of Males and Females Field experiments that investigated the activity patterns of male and female adults during the mating season were carried out in unused farmland with sparse vegetation near the village of Embuay Bad in Ethiopia $\left(09^{\circ} 48^{\prime} \mathrm{N}, 40^{\circ} 00^{\prime} \mathrm{E}\right), 265 \mathrm{~km}$ northeast of Addis Ababa, $1206 \mathrm{~m}$ above sea level, 28 June13 July 2008. Mean daily trap catch was used as an indicator for field activity. For these experiments, traps were baited with half a banana that was mashed and put in the 
collection chamber of the trap, where captured beetles could access it. This bait has previously been shown to be highly attractive to P. interrupta (Ministry of Agriculture and Ethiopian Agricultural Research Organization 1999; Hiwot 2000; Wolde-Hawariat et al. 2007). Traps were placed throughout the site, with a minimum distance of $50 \mathrm{~m}$ between traps. For logistical reasons, we were not able to deploy 10 traps as originally planned throughout the active period ( $N=2$ for 28 June and 3 July, $N=4$ for 29 June-2 July, $N=10$ for 4-9 July, and $N=5$ for 11-13 July). Data were not collected on 10 July.

Pheromone Communication in the Field Field experiments that investigated pheromone communication and host interactions were carried out at Rasa $\left(09^{\circ} 55^{\prime} \mathrm{N}, 40^{\circ} 05^{\prime} \mathrm{E}\right)$, located $255 \mathrm{~km}$ northeast of Addis Ababa, Ethiopia. Experiments were performed 11-16 July and 7-13 October, 2005, in a grazing area characterized by scattered Acacia spp. trees. Live beetles and/or three $1 \mathrm{~cm}$ thick banana slices were placed in fine mesh metal net cages that were fitted into the top of the vanes of the traps. For treatments where beetles of one sex were used as part of the bait, five adults were placed in the mesh cage, whereas for treatments with both males and females as bait, five beetles of each sex were used. For experiments conducted during the mating period (July), beetles that were used as bait were excavated from estivation sites in Rasa during May, before mating had commenced. The beetles used in October were collected in the field during July. Beetles were separated according to sex and kept at the Department of Biology at Addis Ababa University, Ethiopia, under natural light and temperatures ranging between 20 and $25^{\circ} \mathrm{C}$, and fed banana ad libitum until used in experiments. Unbaited traps were included as a negative control.

Identification of Compounds For investigation of female-specific compounds during the mating season, male and female beetles were excavated from estivation sites in the field, near Rasa, during May 2007, and were kept as described above. As mating takes place after the beetles emerge in June-July, in the early part of the rainy period, the beetles excavated were thus assumed to be unmated. As no distinct calling behavior was observed, beetles were selected for extraction by putting a male and female together in a box between 10 am and $2 \mathrm{pm}$, when beetles have previously been observed to mate (unpublished). When the male started clasping the female for mating, they were separated and put in $50 \mathrm{ml}$ Erlenmeyer flasks. Once ten beetles had been added to a flask, redistilled hexane (HPLC grade, Tamro MedLab AB, Gothenburg, Sweden) was added, with just enough hexane to cover the beetles (approximately $5 \mathrm{ml}$ ). After $5 \mathrm{~min}$ with light agitation the solvent was removed and stored for gas chromatography-mass spectrometry (GC-MS) analysis. These extracts were called "first extracts." Next, a similar amount of solvent was added to the beetles and left to stand overnight. The solvent was removed and labeled "second extract." Whole-body extractions as well as extractions of body parts [abdominal tip (outermost $3 \mathrm{~mm}$ ), abdomen without the tip, and all body parts except abdomen] were performed.

GC-MS was used to compare extracts from males and females, and extracts from the different body parts. Analyses were carried out on an HP 6890 Series GC System connected to an HP 5973 Mass Selective Detector (Hewlett-Packard Company, Wilmington, DE, USA) fitted with a BPX5 fused-silica capillary column (25 m x 0.22 mm i.d., $0.25 \mu \mathrm{m}$ film thickness, SGE Inc., Melbourne, Australia). A volume of $1 \mu \mathrm{l}$ was 
injected in splitless mode (60 s valve time), and inlet pressure was $77.1 \mathrm{kPa}$. The GC was programmed as follows: $5 \mathrm{~min}$ at $50^{\circ} \mathrm{C}$ then with $5^{\circ} \mathrm{C} / \mathrm{min}$ to $320^{\circ} \mathrm{C}$, with helium as a carrier gas at a flow rate of $1 \mathrm{ml} / \mathrm{min}$. The transfer line was set to $300^{\circ} \mathrm{C}$. Identification of compounds was performed by comparison of mass spectra and gas chromatographic retention indices with those of synthetic reference compounds. Compounds were regarded as female specific when they occurred repeatedly in females and were absent or present in much lower doses in males. A semi-quantitative analysis of extract

components was conducted by adding pure nonanal as an internal standard. No response factors were determined.

Table 1 Treatments for field tests of flight response of Pachnoda interrupta to femaleproduced compounds, Embuay Bad, Ethiopia, July 2008

\begin{tabular}{|c|c|c|c|c|c|}
\hline $\mathrm{No}^{\mathrm{a}}$ & Treatment & Dispenser & Dose & Purity & CAS \\
\hline 1 & Propyl acetate & capped vial, distal application & $50 \mathrm{mg}$ & $>99.7 \%$ & $109-60-4$ \\
\hline 2 & 1-Methylpropyl acetate & capped vial, distal application & $50 \mathrm{mg}$ & $>99 \%$ & $105-46-4$ \\
\hline 4 & 3-Methylbutyric acid & cotton roll in vial & $50 \mathrm{mg}$ & $>98 \%$ & $503-74-2$ \\
\hline 5 & 2-Methylbutyric acid & cotton roll in vial & $50 \mathrm{mg}$ & $>98 \%$ & $600-07-7$ \\
\hline 6 & Hexanoic acid & cotton roll & $100 \mathrm{mg}$ & $>99.5 \%$ & $142-62-1$ \\
\hline 7 & $(+)$ - $\alpha$-Pinene & capped vial, distal application & $50 \mathrm{mg}$ & $98 \%$ & $80-56-8$ \\
\hline 7 & (-)- $\alpha$-Pinene & capped vial, distal application & $50 \mathrm{mg}$ & $99 \%$ & $80-56-8$ \\
\hline 8 & (1S)-(-)- $\beta$-Pinene & capped vial, distal application & $50 \mathrm{mg}$ & $99 \%$ & $18172-67-3$ \\
\hline 9 & $p$-Cymene & capped vial, centered application & $100 \mathrm{mg}$ & $99 \%$ & $99-87-6$ \\
\hline 10 & $(S)-(-)$-Limonene & capped vial, centered application & $100 \mathrm{mg}$ & $95 \%$ & $5989-54-8$ \\
\hline 10 & $(R)-(+)$-Limonene & capped vial, centered application & $100 \mathrm{mg}$ & $98 \%$ & $5989-27-5$ \\
\hline 11 & Phenylacetaldehyde & cotton roll & $100 \mathrm{mg}$ & $95 \%$ & $122-78-1$ \\
\hline 12 & Benzoic acid ${ }^{b}$ & cotton roll & $65 \mathrm{mg}$ & $>99.5 \%$ & $65-85-0$ \\
\hline 13 & Octanoic acid & cotton roll & $200 \mathrm{mg}$ & $>98 \%$ & $124-07-2$ \\
\hline 14 & (E)-2-Decenal & cotton roll & $100 \mathrm{mg}$ & $>95 \%$ & $3913-81-3$ \\
\hline 15 & Indole & cotton roll & $65 \mathrm{mg}$ & $>99 \%$ & $120-72-9$ \\
\hline 16 & $(E)$-2-Undecenal & cotton roll & $100 \mathrm{mg}$ & $>90 \%$ & $53448-07-0$ \\
\hline 17 & Geranylacetone & cotton roll & $100 \mathrm{mg}$ & $>97 \%$ & $689-67-8$ \\
\hline 18 & $(2 E, 4 E)-2,4-$ Dodecadienal & cotton roll & $50 \mathrm{mg}$ & $>90 \%$ & 21662-16-8 \\
\hline 19 & 4-Dodecanolide & cotton roll & $200 \mathrm{mg}$ & $>99.5 \%$ & $2305-05-7$ \\
\hline- & Mixture ${ }^{c}$ & plastic container / as above & as above & as above & as above \\
\hline- & Unmated females & mesh cage & 5 beetles & $\mathrm{n} / \mathrm{a}$ & $\mathrm{n} / \mathrm{a}$ \\
\hline- & Males & mesh cage & 5 beetles & $\mathrm{n} / \mathrm{a}$ & $\mathrm{n} / \mathrm{a}$ \\
\hline- & Control - tetrahydrofuran & cotton roll & $200 \mathrm{mg}$ & $>99 \%$ & $109-99-9$ \\
\hline- & Control - empty & none & none & $\mathrm{n} / \mathrm{a}$ & $\mathrm{n} / \mathrm{a}$ \\
\hline
\end{tabular}

${ }^{\mathrm{a}}$ The numbers refer to Fig. 5 .

${ }^{\mathrm{b}} 200 \mathrm{mg}$ of $33 \%$ solution in tetrahydrofuran.

${ }^{c}$ All single compounds (including optical isomers) present in individual dispensers put together in a plastic container.

Field Testing of Female-specific Compounds Compounds found by GC-MS to be specific to females during the mating season were tested in the field. Synthetic compounds (for purity and CAS number, see Table 1) were purchased (Sigma-Aldrich Sweden AB, Stockholm, Sweden). Emission rates for dispensers were tested in a cylindrical wind tunnel $\left(1 \mathrm{~m}\right.$ long, $60 \mathrm{~cm}$ diameter, $0.25 \mathrm{~m} / \mathrm{sec}$ air flow, $\left.25^{\circ} \mathrm{C}\right)$ in Alnarp, Sweden. Dispensers were replaced in the field each morning, just before the active period of adult $P$. interrupta, which are day-active (Grunshaw 1992), and release rates were calculated for the first $8 \mathrm{~h}$. Dispensers were weighed after loading, and then weighed again after 1, 2, 4, 6, and $8 \mathrm{~h}$ in the wind tunnel. For comparison, we determined the release rates in this wind tunnel for plant compound lures that had 
previously been shown to be attractive in the field (Wolde-Hawariat et al. 2007). These were found to have a release rate of $0.5-1 \mathrm{mg} / \mathrm{h}$ during the $8 \mathrm{~h}$ measurement period. Based on this analysis, we chose combinations of dose and dispenser for the female compounds that ensured a similar emission rate for each compound.

The least volatile compounds were put on cotton rolls (no. 2 dental cotton roll, Demedis GmbH, Langen, Germany) without any further modification ("cotton roll," Table 1). For more volatile compounds, cotton rolls were pushed into $4 \mathrm{ml}$ glass vials (45 x $14.7 \mathrm{~mm}$, clear, Skandinaviska GeneTec AB, Västra Frölunda, Sweden) until the cotton was level with the rim of the opening of the vial ("cotton roll in vial," Table 1). The test compounds were applied to the cotton roll after placement in the vial. For the most volatile compounds, a cotton roll was put inside a vial closed with a cap (black, closed top, $13 \mathrm{~mm}$, Skandinaviska GeneTec AB). A hole ( $2 \mathrm{~mm}$ diameter) was made in the cap, and the cotton roll was placed so that it was in direct contact with the cap when the cap was screwed tightly to the vial. Two variants were made of this dispenser: 1) one for the most volatile compounds, where the chemical was applied towards the edge of the vial ("capped vial, distal application," Table 1) and 2) one for compounds that were less volatile, where the chemical was applied just underneath the hole in the cap ("capped vial, centered application," Table 1). All compounds were applied neat, apart from indole and benzoic acid (solid at room temperature), which were dissolved in tetrahydrofuran ( $99+\%$ by GC, Sigma-Aldrich Sweden AB) at a concentration of $33 \%$.

Table 2 Volatile female-specific compounds identified from Pachnoda interrupta

\begin{tabular}{llcccl}
\hline $\mathbf{N o}^{\mathbf{a}}$ & Compound & $\begin{array}{c}\text { Estimated } \\
\text { amount }^{\mathbf{b}} \\
\text { (ng) }\end{array}$ & \multicolumn{2}{c}{ Extraction } & \multicolumn{2}{c}{$\begin{array}{c}\text { Present in } \\
\text { body part }\end{array}$} \\
\hline 1 & Propyl acetate & 1.3 & - & + & Tip of abdomen only \\
2 & 1-Methylpropyl acetate & 0.19 & - & + & Tip of abdomen only \\
3 & 2-Methylpropyl acetate & 0.42 & - & + & Tip of abdomen only \\
4 & 3-Methylbutyric acid & 0.18 & - & + & Tip of abdomen only \\
5 & 2-Methylbutyric acid & 0.18 & - & + & Tip of abdomen only \\
6 & Hexanoic acid & 0.07 & - & + & Tip of abdomen only \\
7 & a-Pinene & 0.04 & + & + & All body parts \\
8 & B-Pinene & 0.07 & + & + & All body parts \\
9 & p-Cymene & 0.05 & + & + & All body parts \\
10 & Limonene & 0.05 & + & + & All body parts \\
11 & Phenylacetaldehyde & 0.17 & - & + & Tip of abdomen only \\
12 & Benzoic acid & 0.11 & - & + & Tip of abdomen only \\
13 & Octanoic acid & 0.10 & - & + & Tip of abdomen only \\
14 & (E)-2-Decenal & 0.36 & - & + & Tip of abdomen only \\
15 & Indole & 0.84 & - & + & Tip of abdomen only \\
16 & (E)-2-Undecenal & 0.15 & - & + & Tip of abdomen only \\
17 & Geranylacetone & 0.005 & + & + & All body parts \\
18 & (2E,4E)-2,4-Dodecadienal & 0.15 & - & + & Tip of abdomen only \\
19 & 4-Dodecanolide & 0.02 & - & + & Tip of abdomen only \\
\hline
\end{tabular}

${ }^{\mathrm{a}}$ The numbers refer to Fig. 5 .

${ }^{b}$ The estimated amounts per individual were determined from the second extracts of female abdominal tips without an analysis of the response factors of the authentic standards on the GCMS instrument. The presence or absence in first and second extracts from females is indicated by + or -. These compounds were not present in first or second extracts from males.

${ }^{\mathrm{c}}$ Enantiomeric composition not determined. 
Each compound was tested singly and in a mixture. In the mixture, all compounds were applied to individual dispensers, placed together in a round plastic container (diameter 68 $\mathrm{mm}$, height $30 \mathrm{~mm}$, Semadeni, Ostermundingen, Switzerland) and secured with metal wire. For comparison, treatments were also included with live unmated male and female $P$. interrupta in wire mesh cages as bait. Beetles that were used as bait were excavated from estivation sites near Rasa in May 2008, separated by sex, and kept at the Department of Biology of Addis Ababa University as described above. Experiments were performed 10-12 July, 2008, at Embuay Bad (see above). The experimental design followed the general procedure outlined above, with two exceptions: $N=5$ was used and treatments were moved one position within blocks daily before replacing the dispensers, to decrease the influence of position effects. The tests were conducted when the male bias in sex ratio of beetles caught by positive control traps got less pronounced, during the last three days of the active season in July 2008 (see also results, field activity patterns of male and female beetles).

Statistical Analyses For the statistical evaluation of data from the field experiments, cumulative trap catch over the field testing period was used. Male and female responses were treated separately. Treatments with a mean trap catch of females or males below 1 were excluded (no treatment had a mean trap catch below 1 for one sex while having a mean trap catch above 1 for the other sex). For the remaining treatments, trap catch was $\log _{10}$-transformed before analysis with a General Linear Model (GLM), with treatment (type of lure) as a fixed effect, and block as a random effect (Minitab 14 for Windows). If there were significant effects in the GLM procedure, we compared treatment means by using a Tukey's post hoc test. Within each experiment, sex ratios of treatments (excluding those with a mean trap catch below 1) were compared to those of a positive control by using 95\% binomial confidence intervals (Newcombe 1998), with the Bonferroni correction for multiple comparisons. The significance level used in all tests was $\alpha=0.05$. For all experiments, data is presented in graphs as back-transformed means, with error bars denoting the standard error of the mean.

\section{Results}

Field Activity Patterns of Males and Females Male P. interrupta showed higher flight activity for most of the period during the mating season (Fig. 1); female flight was delayed. During the first $8 \mathrm{~d}$ of the trapping period, the mean trap catch was moderate (the highest mean daily catch was 29 beetles per trap) and there was a strong male bias in catch $(>90 \%)$. From July 7 , beetle activity increased, but the proportion of females remained low. Female activity drastically increased on 12 July, making the sex ratio approximately even. With the onset of heavy rains (13 July 2008), the beetles ceased flying and were not observed mating or feeding on hosts. 


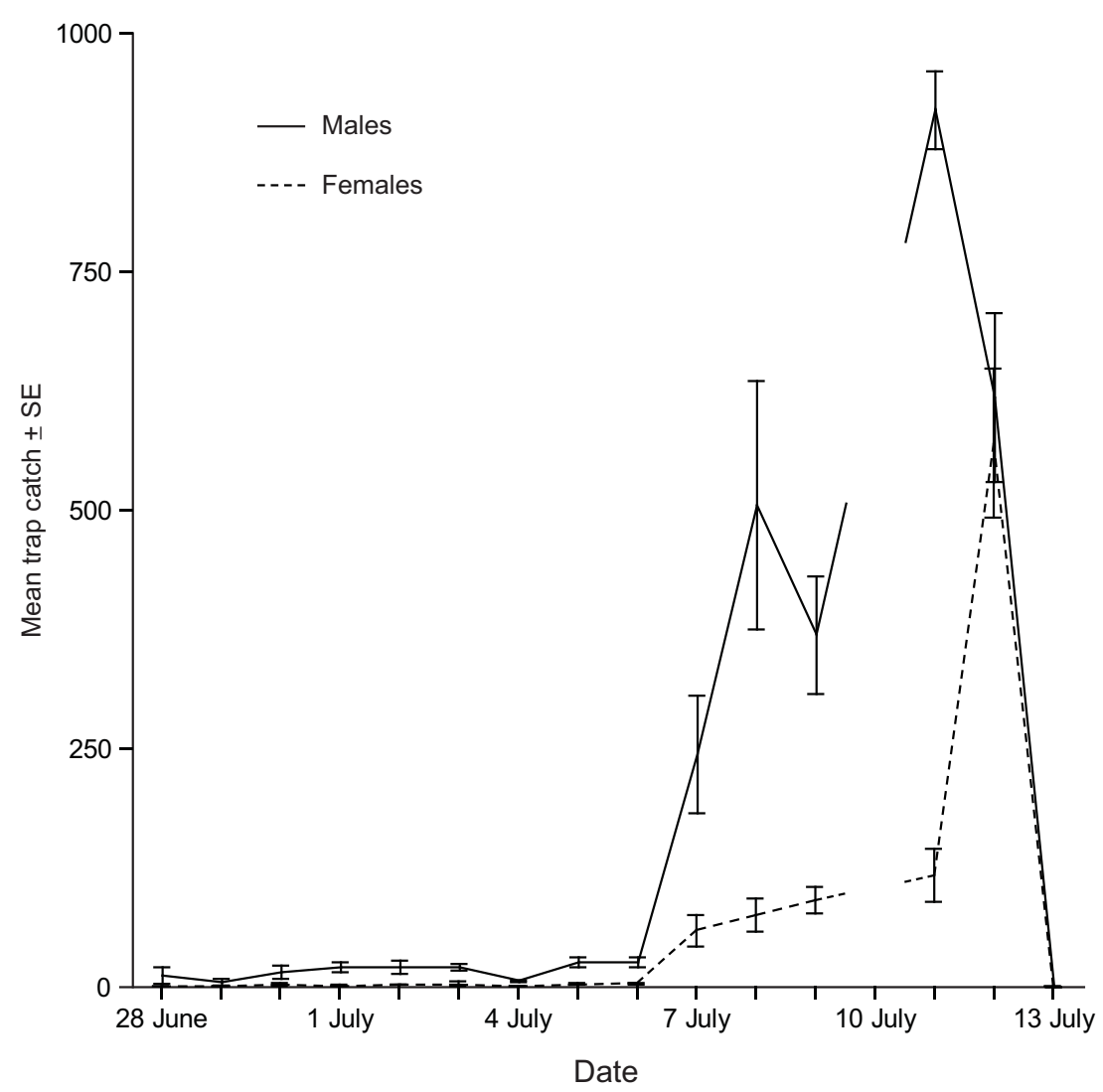

Fig. 1 Flight responses (trap catch) of male (solid line) and female (dashed line) Pachnoda interrupta to mashed banana, 28 June to 13 July 2008, Embuay Bad, Ethiopia. Error bars show standard error of the mean, and sample sizes were $N=2$ (28 June, 3 July), $N=4$ (29 June-2 July), $N=10$ (4-9 July), and $N=5$ (11-13 July). The break in the line denotes that no trap catch data were collected on 10 July.

Pheromone Communication in the Field During the mating period in July, traps baited with unmated females caught a significantly higher proportion of males than the positive control traps (baited with mashed banana in the collection chamber; Fig. 2, 3). The sex ratio caught by other treatments did not differ significantly from the positive control. Few beetles ( 1 or less of each sex) were attracted to traps baited with males, males together with females, or unbaited traps (negative control). Unmated females combined with food (three $1 \mathrm{~cm}$-thick slices of banana) caught significantly more males than any other treatment, but also attracted females to the extent that the sex ratio did not differ significantly from that of the positive control traps. Traps baited with males and food or both sexes and food did not catch significantly more than traps baited with banana slices alone. In October, the newly emerged adults were not attracted to traps baited with beetles alone, neither to males, females, or both sexes together (Fig. 4). Traps baited with combinations of beetles and food, however, were significantly more attractive than traps baited with food alone. The highest catch was obtained in traps baited with both sexes and food, followed by traps baited with males and food. 


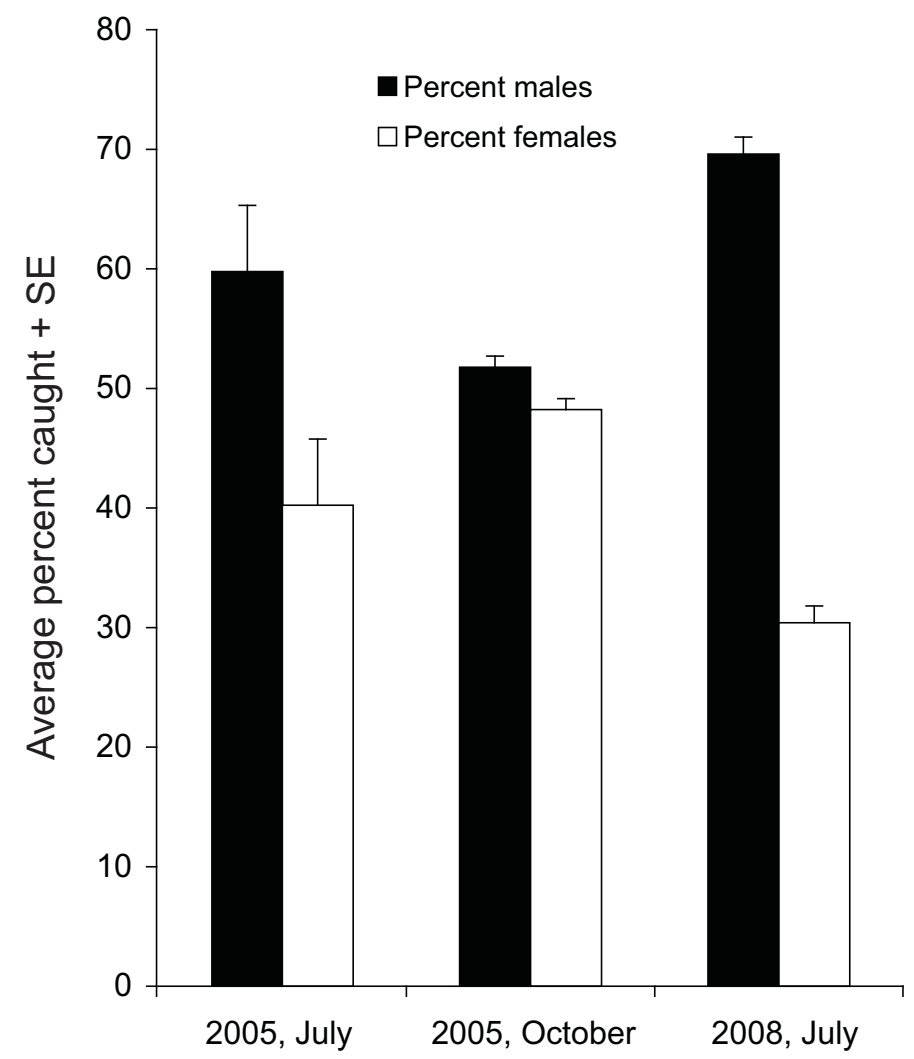

Fig. 2 Percentage male and female Pachnoda interrupta in positive control traps baited with mashed banana July 2005, October 2005, and July 2008 showing the differing sex ratios.

Identification of Female-specific Compounds Extracts obtained during the mating season from male and female beetles were dominated by hydrocarbons and fatty acids, typical constituents of the insect cuticle and fat body. Small amounts of more volatile compounds were also identified (Fig. 5). The monoterpenes $\alpha$-pinene, $\beta$-pinene, $p$ cymene, and limonene as well as geranylacetone were present in female first extracts from all parts of the body, but were absent in male extracts. The female second extracts also contained these compounds, and 14 additional female-specific compounds, which were identified in extracts from the abdominal tip (Table 2). The identified compounds were short chain carboxylic acids, esters, aromatic compounds, and aldehydes. Indole, propyl acetate, and 2-methylpropyl acetate were found in the largest estimated quantities.

Field Testing of Female Compounds The female-specific compounds were tested in the field. Two enantiomers of $\alpha$-pinene, one enantiomer of $\beta$-pinene, and two enantiomers of limonene were included (Table 1), since the enantiomeric composition of these compounds in the natural product was unclear. The peak corresponding to 2methylpropyl acetate was not clearly identified at the time of field testing, and this compound was not included. Traps baited with phenylacetaldehyde caught dramatically more beetles than all other treatments (Fig. 6), catching a mean of 1191 beetles per trap, compared to a mean of 64 beetles per trap for hexanoic acid, the second most attractive compound. The mixture of all compounds caught significantly less than did 


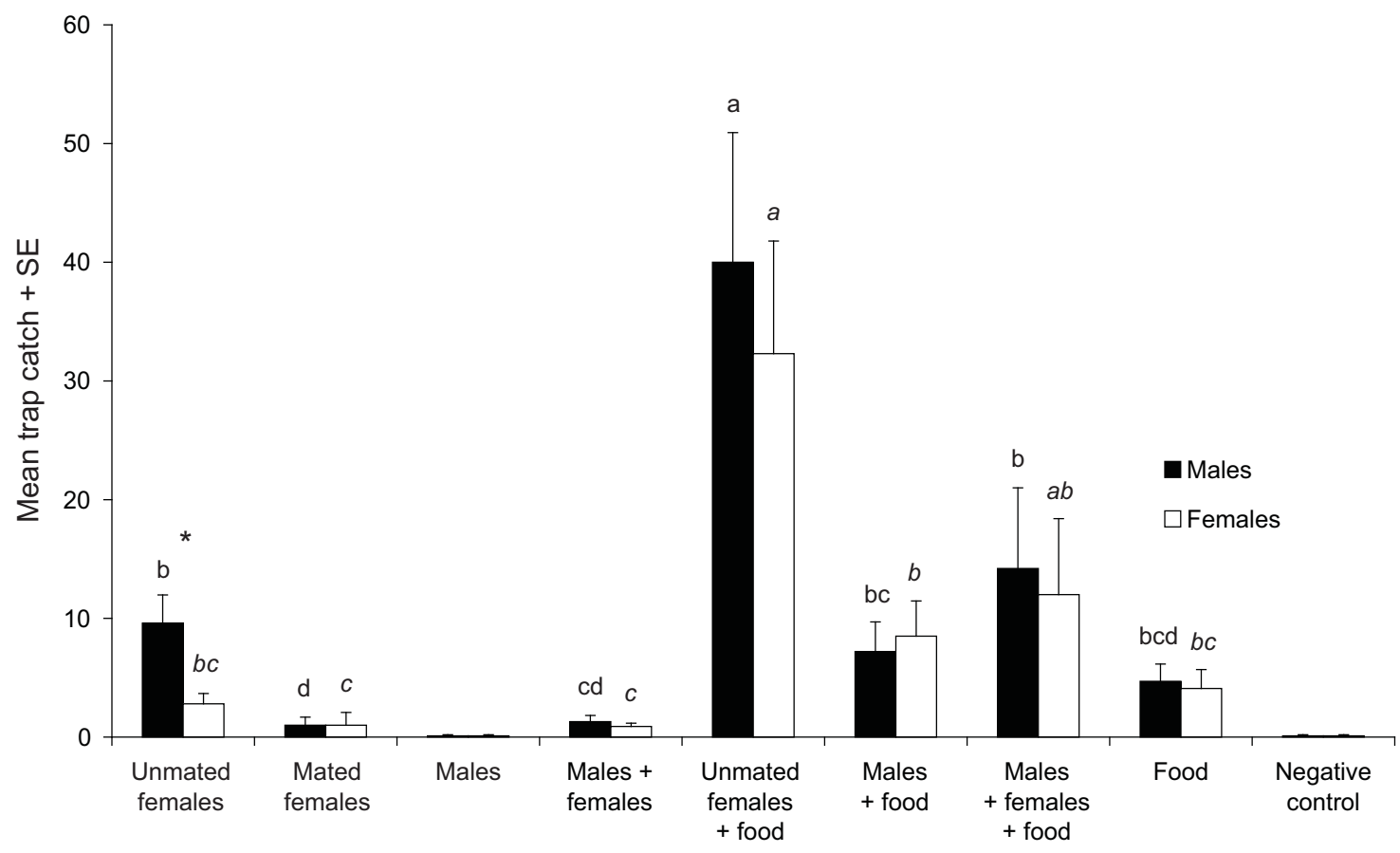

Fig. 3 Flight responses (trap catch) of both sexes of Pachnoda interrupta to various combinations of beetles and food (banana), 11-16 July 2005, Rasa, Ethiopia. Subgroups (males-normal font; femalesitalicized font) denoted by different letters are significantly different $(\alpha=0.05$, Tukey's $b$ on transformed data). Error bars show standard error of the mean and sample size was $N=10$. Treatments marked by asterisks differed significantly from the positive control (Fig. 2) in sex ratio. Data from treatments with a mean trap catch below 1 were not included in the statistical analysis.

phenylacetaldehyde alone, whereas no treatment caught significantly less than unbaited traps or traps baited with solvent alone (negative controls). Sex ratios were male-biased for all treatments and did not differ significantly among treatments and the positive control (traps baited with mashed banana).

\section{Discussion}

Field trapping with live beetles as bait showed that during the mating period, unmated female $P$. interrupta were particularly attractive to males (Fig. 3), indicating that a female-emitted sex pheromone is present. However, females were also attracted, albeit to a far lower degree than males. With scarabs, the attraction of both sexes to a femaleproduced pheromone has also been observed in the Japanese beetle, Popillia japonica Newman (Potter and Held 2002), and opportunistic attraction of same-sex individuals to sex pheromones has been implied as a mechanism in the formation of aggregations in bark beetles (Schlyter and Birgersson 1999). The reason for the lack of male-biased attraction to unmated females in a later field study (Fig. 6) is unknown, but, as the mating period is brief, a possible explanation could be that the beetles had either passed or not yet reached mating maturity.

In June-July, $P$. interrupta form large aggregations on Acacia spp. trees where they feed and mate, and the most obvious underlying reasons for the observed female 


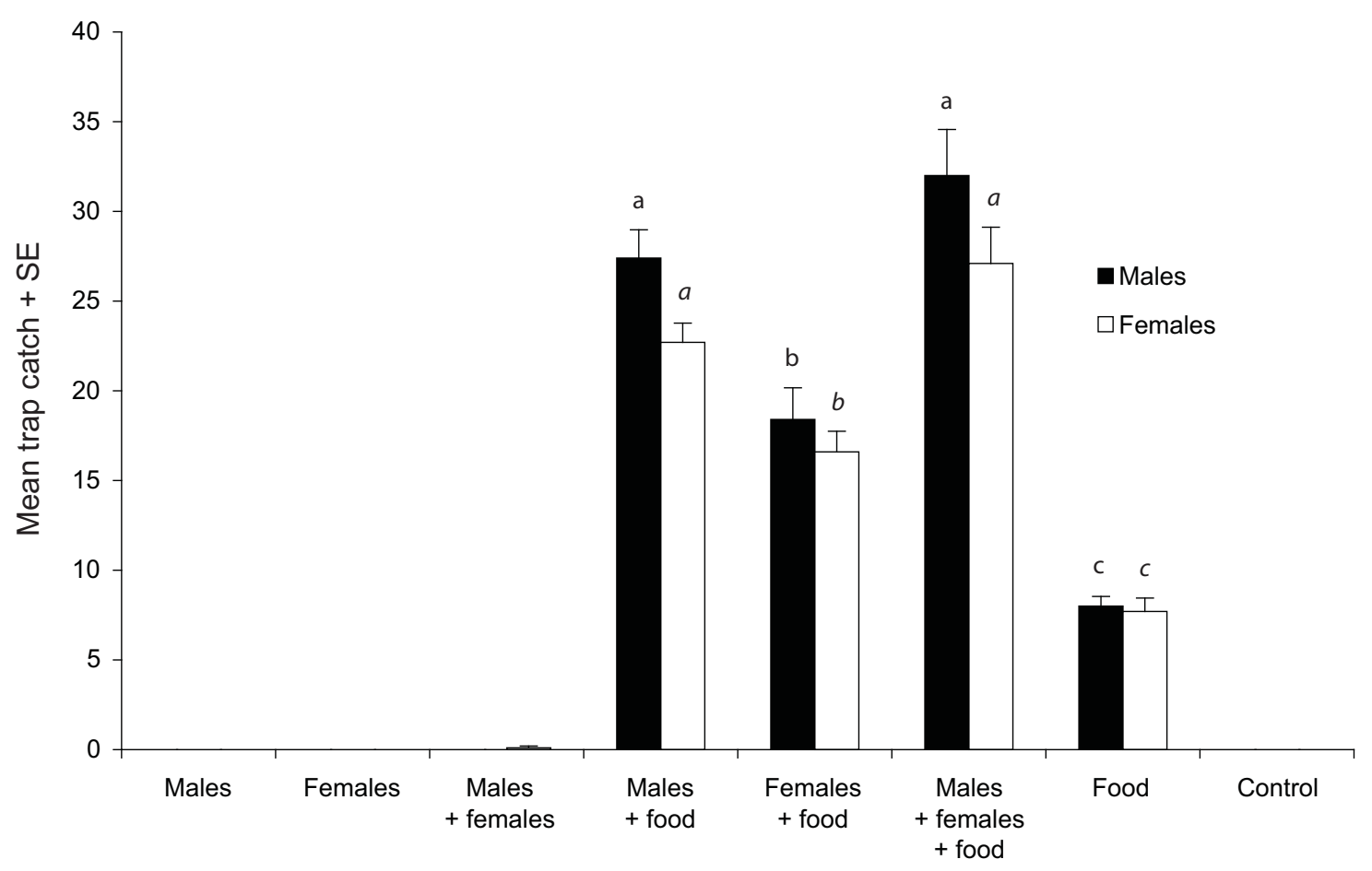

Fig. 4 Flight responses (trap catch) of both sexes of Pachnoda interrupta to various combinations of beetles and food (banana), 7-13 October 2005, Rasa, Ethiopia. Subgroups (males-normal font; femalesitalicized font) denoted by different letters are significantly different $(\alpha=0.05$, Tukey's $b$ on transformed data). Error bars show standard error of the mean and sample size was $N=10$. No treatments differed significantly from the positive control (Fig. 2) in sex ratio. Data from treatments with a mean trap catch below 1 were not included in the statistical analysis.

attraction are facilitation of food and mate finding, as has been suggested for other insect species (Thornhill and Alcock 1983). The aggregations have been observed to increase in frequency and size later in the mating season. This could be linked to the observed delay in female flight activity (Fig. 1), since the aggregations are likely to be caused by an interaction between the female pheromone signaling system and the host, as evidenced by the strong attraction of both sexes to unmated females combined with food (banana) (Fig. 3). In other insects, increased attraction has been observed to combinations of pheromones with volatiles from hosts used for feeding (Klein et al. 1981, Seybold et al. 2006), oviposition (Dickens et al. 1993), or both (Bartelt et al. 1985), and shifts in sex ratio of attracted conspecifics when unmated females are combined with food volatiles have been observed in P. japonica (Klein et al. 1981) and the diamondback moth, Plutella xylostella (L.) (Reddy and Guerrero 2000). Access to food could also increase pheromone emission by females (McNeil and Delisle 1989), and aggregations might be influenced by pheromone release rate as well as the presence of host volatiles.

Insects may also alter the profile of volatile compounds emitted by their hosts by feeding damage or by inoculation with microorganisms (Zagatti et al. 1997; MacíasSámano et al. 1998; Wertheim et al. 2002). In scarabs, adults feeding on plant hosts have been shown to induce emission of volatiles that facilitate aggregation (Harari et al. 1994), as well as mating behavior (Ruther et al. 2002). However, as we did not observe an increase in attraction during the mating season when we combined food with males, or 

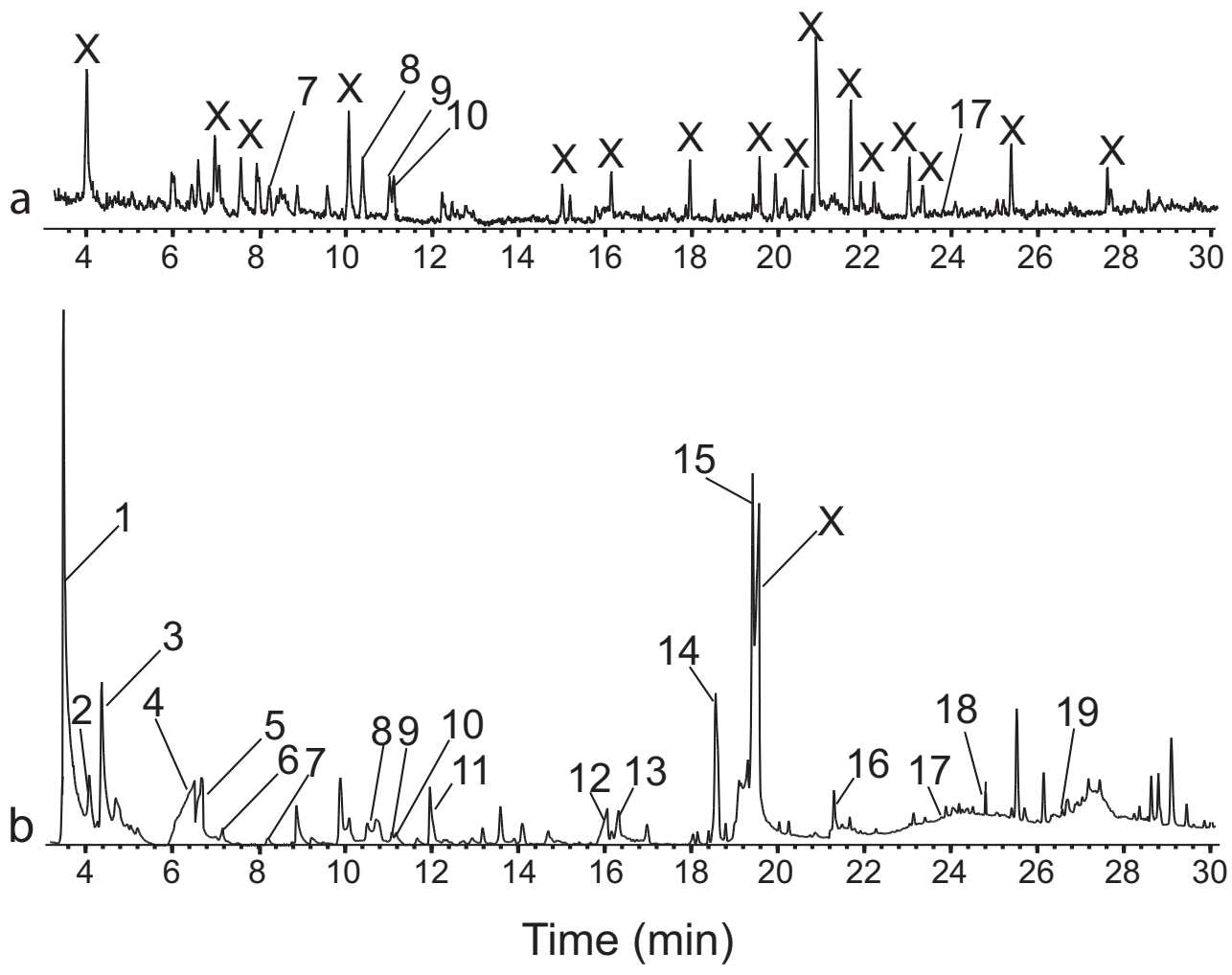

Fig. 5 Enlarged part of gas chromatograms of hexane extract of the abdominal tip of female Pachnoda interrupta during the mating season. (a) First extraction. (b) Second extraction. 1. Propyl acetate; 2.1Methylpropyl acetate; 3. 2-Methylpropyl acetate; 4. 3-Methylbutyric acid; 5. 2-Methylbutyric acid; 6. Hexanoic acid; 7. $\alpha$-Pinene; 8. $\beta$-Pinene; 9. p-Cymene; 10. Limonene; 11. Phenyacetaldehyde; 12. Benzoic acid; 13. Octanoic acid; 14. (E)-2-Decenal; 15. Indole; 16. (E)-2-Undecenal; 17. Geranylacetone; 18. (2E,4E)-2,4-Dodecadienal; and 19. 4-Dodecanolide (numbers as in Table 2). The symbol X indicates artifacts comprising silicone derivatives from the column and hydrocarbon impurities from the solvent.

with both sexes together (Fig. 3), it is unlikely that the synergy in attraction to unmated females with food during the mating season is due to a change in the volatile profile emitted by the food. During October, adult beetles are active above ground for 1-2 wk and feed (but do not mate) before going into estivation. Accordingly, unmated females were not attractive to males during this period (Fig. 4), whereas a combination of either or both sexes with food increased attraction above that to food alone. Possible mechanisms behind this increase in attraction are changes to the volatile profile of the host by feeding or inoculation with microorganisms, which however would contrast with the seeming lack of importance of such changes during the mating season.

Field testing of synthetic female-unique compounds established that phenylacetaldehyde (PAA), a common constituent of flower volatiles (reviewed in Knudsen et al. 2006), was highly attractive to males (Fig. 6). We hypothesize that PAA is a female-produced pheromone component for $P$. interrupta, but this will need to be proved through biochemical labeling or other approaches. No pheromones have been described for scarab species of the subfamily Cetoniinae, but other scarab species exhibit considerable diversity in pheromone semiochemistry, and several small aromatic 


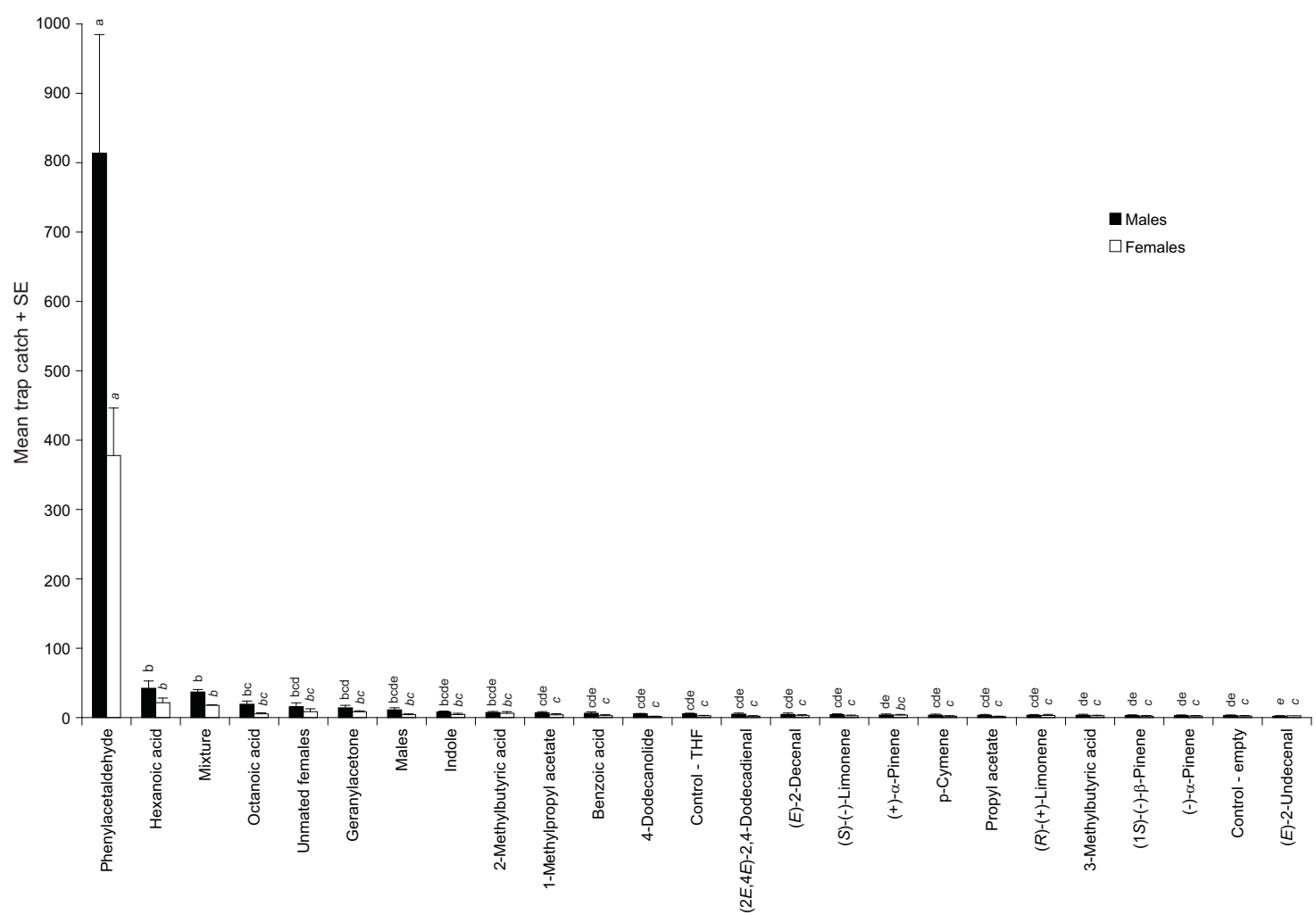

Fig. 6 Flight responses (trap catch) of both sexes of Pachnoda interrupta to various potential femaleassociated semiochemicals, 10-12 July 2008. Subgroups (males-normal font; females-italicized font) denoted by different letters are significantly different ( $\alpha=0.05$, Tukey's $b$ on transformed data). Error bars show the standard error of the mean and the sample size was $N=5$. No treatments differed significantly from the positive control (Fig. 2) in sex ratio.

compounds have been identified as pheromone components (e.g., phenol, anisole, and methyl benzoate) (reviewed in Leal 1998). On the other hand, some scarab attractants have been found in flowers (Knudsen et al. 2006), and the use of plant volatiles, including PAA (Honda 1980; Bellas and Hölldobler 1985), as attractants with pheromones has been observed in several insects (Boch and Shearer 1962; Baker 1989; Eller et al. 1994; Hassanali et al. 2005; Bartelt et al. 2009; Kim et al. 2009).

In agreement with the results of the field experiments where unmated females attracted both sexes, female $P$. interrupta were also attracted to PAA (Fig. 6). The strong attraction of both sexes to traps baited with PAA might in part be a dose effect, as suggested above concerning aggregations. We estimated that the release rate of PAA was $0.5-1 \mathrm{mg} / \mathrm{h}$ from the field lures. Although individual females only contained an estimated $0.2 \mathrm{ng}$ of PAA, during the mating season, $P$. interrupta form aggregations with thousands of adults and the effective emission of PAA from one of these aggregations may be quite high. High release rates of semiochemicals have been shown to be necessary for attraction in the Coleoptera, e.g., to pheromone components in Ips typographus (L.) (Schlyter et al. 1987) or to host attractant monoterpenes in many other bark beetles (reviewed in Seybold et al. 2006). Furthermore, the involvement of additional components in the pheromone communication system of $P$. interrupta cannot be ruled out, and the inclusion of such compounds might enhance the specificity of the signal, and lower the threshold for response (Linn et al. 1986). Practical limitations forced us to 
forego extensive field testing of blends, and a treatment including all identified femaleunique compounds proved to be less attractive than the treatment with PAA alone (Fig. $6)$.

The high level of attraction to the putative pheromone compound PAA is promising for future application. Both sexes are attracted, and traps catch adults, which is the life stage causing damage in this system. Trapping has proven efficient for control in other pest species where adults are the damaging stage (reviewed by Witzgall et al. 2010). PAA could be combined with previously identified host-related attractants, such as 2,3-butanediol (Bengtsson et al. 2009), eugenol, and methyl salicylate (WoldeHawariat et al. 2007) for evaluation of synergistic effects, and to further improve the attractiveness of lures. Such lures could be powerful instruments for monitoring, but also for mass trapping of $P$. interrupta.

Acknowledgments We thank the Plant Protection and Regulatory Department of the Ministry of Agriculture and Rural Development of Ethiopia for providing traps for the field trapping experiment. This work was financed mainly by a grant from the Swedish International Development Agency (Sida/SAREC) for which the authors are grateful. In addition, Swedish support was supplied by the IC- $\mathrm{E}^{3}$ Linnaeus program. The authors are also grateful for financial support provided by the Ethiopian Institute of Agricultural Research, especially the secretariat for the Agricultural Research Fund. Generous stipends from the Lars Hiertas Minne and Ångpanneföreningen Trusts helped finance the field experiments in this study. The authors would also like to thank Dr. Mattias C. Larsson for valuable comments on the manuscript.

\section{References}

Alpizar, D., Fallas, M., Oehlschlager, A. C., Gonzalez, L. M., Chinchilla, C. M., and BUlgarelli, J. 2002. Pheromone mass trapping of the west Indian sugarcane weevil and the American palm weevil (Coleoptera: Curculionidae) in palmito palm. Florida Entomol. 85:426-430.

BAKER, T. 1989. Origin of courtship and sex pheromones of the oriental fruit moth and a discussion of the role of phytochemicals in the evolution of lepidopteran male scents. pp. 401-418, in C. Chou and G. Waller (eds.). Phytochemical Ecology: Allelochemicals, Mycotoxins and Insect Pheromones and Allomones. Academia Sinica Monograph Series, Taipei, Taiwan.

BARTELT, R. J., SCHANER, A. M., and JACKSON, L. L. 1985. cis-Vaccenyl acetate as an aggregation pheromone in Drosophila melanogaster. J. Chem. Ecol. 11:17471756.

Bartelt, R. J., Zilkowski, B. W., Cosse, A. A., Steelman, C. D., and Singh, N. 2009. Male-produced aggregation pheromone of the lesser mealworm beetle, Alphitobius diaperinus. J. Chem. Ecol. 35:422-434.

Bellas, T. and HölldOBler, B. 1985. Constituents of mandibular and Dufour's glands of an Australian Polycharis weaver ant. J. Chem. Ecol. 11:525-538.

Bengtsson, J. M., Wolde-Hawariat, Y., Khbaish, H., Negash, M., Jembere, B., Seyoum, E., Hansson, B. S., LARSSON, M. C., and Hillbur, Y. 2009. Field 
attractants for Pachnoda interrupta (Coleoptera: Scarabaeidae): Identification by means of GC-EAD and single sensillum screening. J. Chem. Ecol. 35:1063-1076.

BOCH, R. and SHEARER, D. A. 1962. Identification of geraniol as the active component in the Nassanoff pheromone of the honey bee. Nature 194:704-706.

Clark, R. O. S. and Crowe, T. J. 1978. The genus Pachnoda in Ethiopia. Identification, pest status and control of the species. - Institute of Agricultural Research, Addis Ababa, Ethiopia.

Dickens, J., SMith, J., and Light, D. 1993. Green leaf volatiles enhance sex attractant pheromone of the tobacco budworm, Heliothis virescens (Lep.: Noctuidae). Chemoecol. 4:175-177.

Eller, F. J., Bartelt, R. J., Shasha, B. S., Schuster, D. J., Riley, D. G., Stansly, P. A., Mueller, T. F., Shuler, K. D., and Johnson, B. 1994. Aggregation pheromone for the pepper weevil, Anthonomus eugenii Cano (Coleoptera: Curculionidae): Identification and field activity. J. Chem. Ecol. 20:1537-1555.

GRUNSHAW, J. P. 1992. Field studies on the biology and economic importance of Pachnoda interrupta (Coleoptera: Scarabaeidae) in Mali West Africa. B. Entomol. Res. 82:19-27.

HARARI, A., BEN-YAKIR, D., and RoSEN, D. 1994. Mechanism of aggregation behavior in Maladera matrida Argaman (Coleoptera: Scarabaeidae). J. Chem. Ecol. 20:361371.

Hassanali, A., NuAgi, P. G. N., and Bashir, M. O. 2005. Chemical ecology of locusts and related acridids. Ann. Rev. Entomol. 50:223-245.

HIwOT, L. 2000. Historical background on the pest status and control of sorghum chafer, Pachnoda interrupta (Coleoptera: Scarabaeidae), in Ethiopia. Workshop on the Development of Monitoring and Control Strategy Against Sorghum Chafer, Pachnoda interrupta (Coleoptera: Scarabaeidae) in Ethiopia, Ministry of Agriculture, Addis Ababa, Ethiopia, pp. 9-15.

HondA, K. 1980. Odor of a Papilionid butterfly. J. Chem. Ecol. 6: 867-873.

JAGO, N. D. 1995. Population monitoring and crop loss assessment in integrated pest management of panicle pests of sorghum and pearl millet. pp. 103-113, in O. Youm (ed.). Panicle Insect Pests of Sorghum and Pearl Millet. ICRISAT, Niamey, Niger.

KIM, J., LEE, S.-G., SHIN, S.-C., KwON, Y.-D., and PARK, I.-K. 2009. Male-produced aggregation pheromone blend in Platypus koryoensis. J. Agric. Food Chem. 57:1406-1412.

Klein, M. G., Tumlinson, J. H., LADD, T. L. J., and DoolitTle, R. E. 1981. Japanese beetle Popillia japonica (Coleoptera: Scarabaeidae) response to synthetic sex attractant plus phenethyl propionate eugenol. J. Chem. Ecol. 7:1-8.

Knudsen, J. T., ERiKSSON, R., Gershenzon, J., and StAhl, B. 2006. Diversity and distribution of floral scent. Botan. Rev. 72:1-120.

LEAL, W. 1998. Chemical ecology of phytophagous scarab beetles. Ann. Rev. Entomol. 43:39-61.

LinN, C. E., CAMPBell, M. G., and Roelofs, W. L. 1986. Male moth sensitivity to multicomponent pheromones: critical role of female-released blend in determining the functional role of components and active space of the pheromone. J. Chem. Ecol. 12:659-668. 
Macías-Sámano, J. E., Borden, J. H., Gries, R., Pierce, H. D., Gries, G., and King, G. G. S. 1998. Primary attraction of the fir engraver, Scolytus ventralis. J. Chem. Ecol. 24:1049-1075.

MCNeIL, J. N. and DelisLE, J. 1989. Host plant pollen influences calling behavior and ovarian development of the sunflower moth, Homoeosoma electellum. Oecologia 80:201-205.

Ministry OF Agriculture, and Ethiopian Agricultural Research Organization. 1999. Control measures used by farmers and associated problems. Workshop on the Significance, Distribution, and Control of Sorghum Chafer, Pachnoda interrupta (Olivier) (Coleoptera: Scarabaeidae) in Amhara and Afar regions, Ministry of Agriculture and Ethiopian Agricultural Research Organization, Addis Ababa, Ethiopia, pp. 19-23.

Newcombe, R. G. 1998. Interval estimation for the difference between independent proportions: comparison of eleven methods. Statistics in Medicine 17:873-890.

Oehlschlager, A. C., Chinchilla, C., Castillo, G., and Gonzalez, L. 2002. Control of red ring disease by mass trapping of Rhynchophorus palmarum (Coleoptera: Curculionidae). Florida Entomol. 85:507-513.

PotTer, D. A. and Held, D. W. 2002. Biology and management of the Japanese beetle. Ann. Rev. Entomol. 47:175-205.

REDDY, G. and Guerrero, A. 2000. Behavioral responses of the diamondback moth, Plutella xylostella, to green leaf volatiles of Brassica oleracea subsp. capitata. J. Agric. Food Chem. 48:6025-6029.

RUther, J., ReINECKE, A., and HiLKeR, M. 2002. Plant volatiles in the sexual communication of Melolontha hippocastani: response towards time-dependent bouquets and novel function of (Z)-3-hexen-1-ol as a sexual kairomone. Ecol. Entomol. 27:76-83.

SastawA, B. M. and LALE, N. E. S. 2000. Efficacy of host plant resistance, sowing date modification and intercropping as methods for the control of Pachnoda interrupta (Olivier) in pearl millet in the Nigerian Sudan savanna. J. Arid Environ. 46:249262.

SCHLYTER, F. and Birgersson, G. 1999. Forest beetles. pp. 113-148, in J. Hardie and A. Minks (eds.). Pheromones of Non-Lepidopteran Insects Associated with Agricultural Plants. CAB International, Oxford, UK.

SCHLYTER, F., LÖFQVIST, J., and BYERS, J. A. 1987. Behavioural sequence in the attraction of the bark beetle Ips typographus to pheromone sources. Physiol. Entomol. 12:185-196.

Schmutterer, H. 1969. Pests of Crops in Northeast Africa and Central Africa. - Gustav Fischer Verlag, Stuttgart, Germany.

Seneshaw, A. and Mulugeta, N. 2002. Study on the biology of the sorghum chafer, Pachnoda interrupta (Coleoptera: Scarabaeidae). Pest Management Journal of Ethiopia 6:31-36.

Seybold, S.J., Huber, D.P.W., Lee, J.C., Graves, A. D., and Bohlmann, J. 2006. Pine monoterpenes and pine bark beetles: A marriage of convenience for defense and chemical communication. Phytochem. Rev. 5:143-178.

ThORNHILl, R. and ALCOCK, J. 1983. The evolution of insect mating systems. Harvard University Press, Cambridge, MA, USA. 
Wertheim, B., Marchais, J., Vet, L. E. M., and Dicke, M. 2002. Allee effect in larval resource exploitation in Drosophila: an interaction among density of adults, larvae, and micro-organisms. Ecol. Entomol. 27:608-617.

WhITE, F. 1983. The vegetation of Africa, a descriptive memoir to accompany the UNESCO/AETFAT/UNSO Vegetation Map of Africa. - UNESCO, Paris, France.

WitzGall, P., KIRSCH, P., and CORK, A. 2010. Sex pheromones and their impact on pest management. J. Chem. Ecol. 36:80-100.

Wolde-Hawariat, Y., Seyoum, E., Jembere, B., Negash, M., Hansson, B. S., and HILLBUR, Y. 2007. Behavioural and electrophysiological response of sorghum chafer Pachnoda interrupta (Coleoptera: Scarabaeidae) to plant compounds. Int. J. Trop. Insect Sci. 27:53-61.

YitBAREK, W. H. and HiwOT, L. 2000. Yield loss assessment of sorghum chafer, Pachnoda interrupta (Coleoptera: Scarabaeidae), in Ethiopia. Workshop on the Development of Monitoring and Control Strategy Against Sorghum Chafer, Pachnoda interrupta (Coleoptera: Scarabaeidae) in Ethiopia, Ministry of Agriculture, Addis Ababa, Ethiopia, pp. 40-43.

Zagatti, P., Lemperiere, G., and Malosse, C. 1997. Monoterpenes emitted by the large pine weevil, Hylobius abietis (L.) feeding on Scots pine, Pinus sylvestris (L.). Physiol. Entomol. 22:394-400. 